Perceptual and Motor Skills, 1999, 89, 994-996. (C) Perceptual and Motor Skills 1999

\title{
HEMISPHERIC LATERALITY AND SELF-RATED PERSONALITY TRAITS ${ }^{\prime}$
}

\author{
WILLIAM D. SCOTT KILLGORE \\ Harvard Medical School \\ LyNN DellaPIETRA, AND DANIEL J. CASASANTO \\ University of Pennsylvania Scbool of Medicine
}

\begin{abstract}
Summary.-Cerebral hemispheric lateralization and personality traits were evaluated in 154 under $\xi^{\prime \prime}$ aduate and nonclinical volunteers. Personality ratings did not differ significantly berween groups defined on the basis of hand, eye, or ear preference.
\end{abstract}

The two cerebral hemispheres have been characterized as possessing different information-processing strategies. For example, the left hemisphere appears to process information in an analytic and detail oriented manner, whereas the right hemisphere seems to process information in a holistic and configurational manner (2). It has been suggested further that there are individual differences in the preference for a particular mode of information processing which may be a function of "hemisphericity," i.e., a tendency for one hemisphere to function in a dominant capacity during most types of cognitive processing (1). According to this perspective, the left-hemisphere dominant individual approaches the world analytically, emphasizing detail and rational examination, whereas the right-hemisphere dominant individual tends to approach situations from a holistic and integrative perspective (1). There has been much interest in the concept of "hemispheric dominance" as related to personality type $(6,8)$, and studies on this topic often report meaningful personality differences between "left-brain" and "right-brain" dominant individuals $(5,11)$. Recent studies have suggested that left hemisphere-dominant individuals tend to be self-controlled, have strong leadership qualities and show traits such as introversion, judging, thinking, and sensing, while right hemisphere-dominant individuals are described as extroverted, independent, intuitive, feeling, and perceptive $(5,11)$.

Some authors, however, caution that claims concerning hemispheric dominance often exceed the scientific evidence and verge on "dichotomania" (10, p. 96). One difficulty is that many studies of personality and hemispheric dominance have been based on somewhat circular logic, using theory

'Please address correspondence to William D. Scott Killgore, Ph.D., Harvard Medical School Brain Imaging Center, McLean Hospital, 115 Mill Street, Belmont, MA 02478 or e-mail (killgore@genesis.mclean.org). 
to define a set of behaviors that are believed to be associated with each hemisphere's preferred style $(7,15)$, and then using this set of behaviors as evidence that each hemisphere is indeed using a different processing strategy (8). A more sound methodology would be to use indices of cerebral laterality that do not depend on personality descriptors for their definition. For example, there is large body of evidence indicating that motor dominance, i.e., hand, foot preference, is associated to a moderate extent with cerebral lateralization of language $(12,14)$. There is also evidence that lateralized sensory dominance is associated with lateralization of higher cognitive processes. For example, eye dominance is significantly predictive of asymmetries in the perception of nonverbal material presented via dichotic listening and visual tachistoscopic techniques (13). Moreover, right-eye dominance appears to be associated with greater representation of language in the left-hemisphere as measured by dichotic listening tasks (3). Self-reported ear-preference has also been shown to be predictive of language lateralization (4). Thus, it may be more appropriate to evaluate the association of personality traits with hemispheric dominance defined on the basis of one or several of these well established indices of laterality.

Therefore, we compared self-reported personality traits for 67 male and 87 female undergraduate and nonclinical volunteers $\left(M_{\text {age }}=32.6\right.$ yr., $S D=$ 14.1) grouped according to three well established indices of hemispheric laterality, i.e., self-reported dominance for hand, eye, and ear preference. Subjects made self-ratings on 5-point Likert-scales for the following 14 personality descriptors: "analytic," "intuitive," "able to see the big picture," "sensitive," "detail-oriented," "emotional," "creative," "follow instructions well," "artistic," "logical," "methodical," "rational," "organized," "socially perceptive."

Independent group $t$ tests showed no mean difference between righthanders $(n=116)$ and left-handers $(n=37)$ for any of the 14 items. When groups were compared according to dominant eye preference, the 82 righteyed subjects $(M=3.7, S D=0.9)$ rated themselves as more "organized" than the 73 left-eyed subjects $\left(M=3.3, S D=1.1 ; t_{153}=-2.01, p=.05\right)$, but no other difference emerged for the other 13 items. For ear preference, there was only a single significant difference, with the 98 right-eared $(M=3.9, S D=1.2)$ subjects rating themselves significantly higher for "follow instructions well" compared to the 57 left-eared persons $\left(M=3.4, S D=1.1 ; t_{153}=-2.17, p=\right.$ $.03)$. Even the two significant differences that emerged presently, however, cannot be considered statistically reliable if any type of correction for multiple comparisons is applied. Thus, within our data we find no compelling evidence for differences in self-rated personality between groups defined by well-established indices of cerebral laterality. These findings are consistent with those of Nestor and Safer who also did not find evidence of hemi- 
spheric dominance for personality variables (9). These findings highlight the need for further study to clarify the relationships between indices of motor and sensory laterality and higher level cognitive processes such as the expression of personality.

\section{REFERENCES}

1. Bogen, J. E. (1977) Some educational implications of hemisphere specialization. In M. C. Wittrock (Ed.), The buman brain. Englewood Cliffs, NJ: Prentice Hall.

2. Bradshaw, J. L., \& Nettreton, N. C. (1981) The nature of hemisphere specialization in man. The Behavioral and Brain Sciences, 4, 51-91.

3. Bryden, M. P. (1988) Correlates of the dichotic right-ear effect. Cortex, 24, 313-319.

4. Brysbaert, M. (1994) Lateral preferences and visual field asymmetries: appearances may have been overstated. Cortex, 30, 413-429.

5. Gadzella, B. M. (1999) Differences among cognitive processing styles groups on personality traits. Journal of Instructional Psychology, 26, 161-166.

6. Hartman, S. E., Hyiton, J., \& Sanders, R. F. (1997) The influence of hemispheric dominance on scores of the Myers-Briggs Type Indicator. Educational and Psycbological Measurement, $57,440-449$.

7. Lueberman, M. G. (1986) The bemispberic mode indicator. Barrington, IL: Excel.

8. McLaughuin, M., \& Lester, D. (1997) Brain hemisphere dominance and personality. Perceptzal and Motor Skills, 85, 786.

9. NeStOR, P. G., \& SAFER, M. A. (1990) A multi-method investigation of individual differences in hemisphericity. Cortex, 26, 409-421.

10. OrnsteIn, R. (1997) The right mind: making sense of the hemispheres. New York: Harcourt Brace.

11. Power, S. J., \& Lundsten, L. L. (1997) Studies that compare type theory and left-brain/ right-brain theory. Journal of Psychological Type, 43, 22-28.

12. Strauss, E. (1986) Hand, foot, eye and ear preferences and performance on a dichotic listening test. Cortex, 22, 475-482.

13. Strauss, E., \& Goldsmith, S. M. (1987) Lateral preferences and performance on non-verbal laterality tests in a normal population. Cortex, 23, 495-503.

14. Strauss, E., \& $W_{A D A}$, J. (1983) Lateral preferences and cerebral speech dominance. Cortex, $19,165-177$.

15. WAGNER, R. F. \& WELLS, K. A. (1985) A refined neurobehavioral inventory of hemispheric preference. Journal of Clinical Psychology, 41, 671-676. 